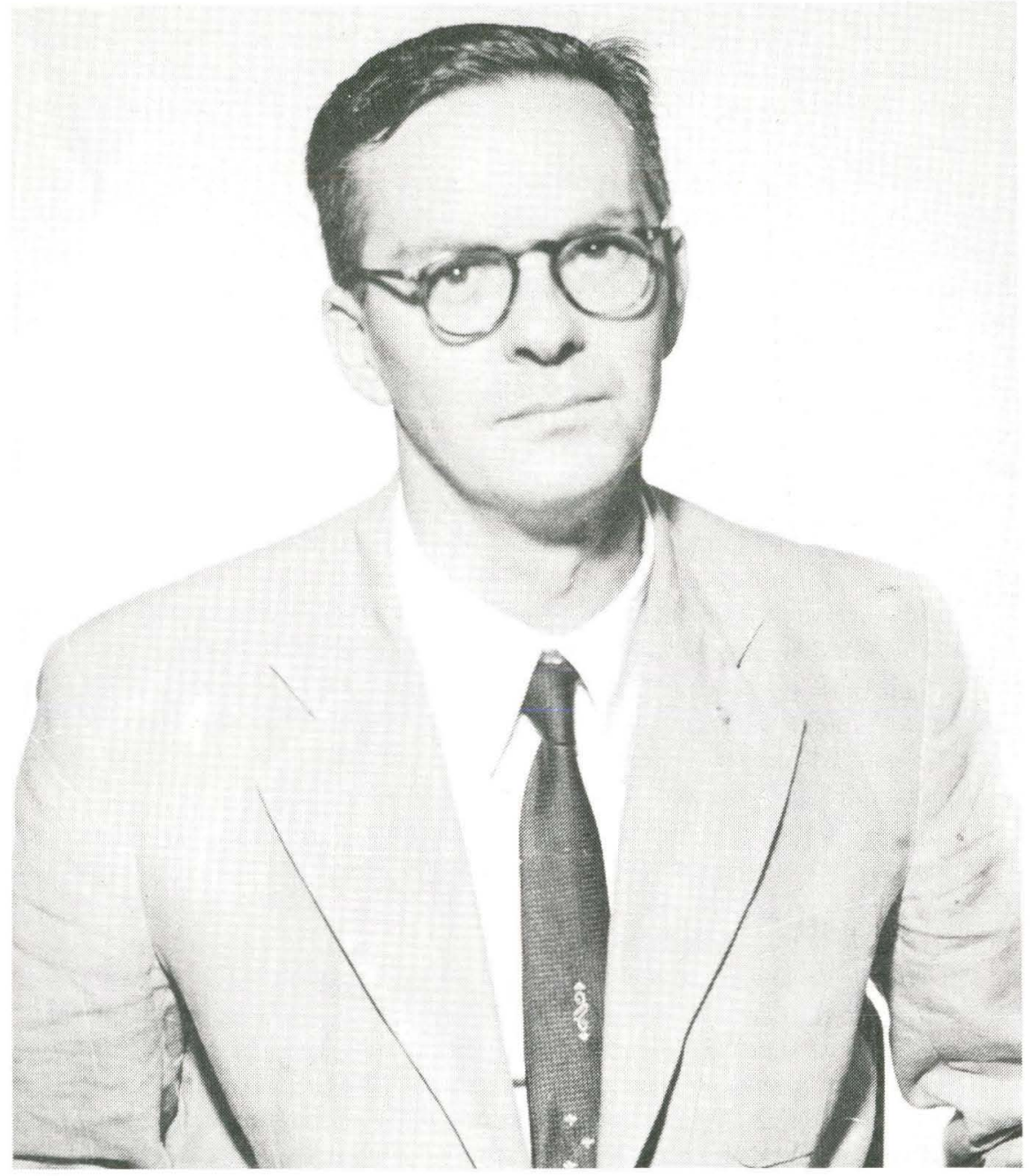

\title{
José Cândido de Mello Carvalho \\ (11.VI.1914 - 21.X.1994) \\ Homenagem da Sociedade Brasileira de Zoologia
}

Em 24 de julho de 1994 recebeu o ilustre Zoólogo, na abertura do XX Congresso Brasileiro de Zoologia, a Medalha de Ouro da Sociedade Brasileira de Zoologia, da qual foi um dos fundadores e o seu primeiro Presidente; foi-lhe concedida a Presidência de Honra; em 09 de setembro do mesmo ano a Presidência da República conferiu-lhe a Ordem Nacional do Mérito Científico, na classe da Grã-Cruz. Foram as últimas grandes homenagens que recebeu em vida. 
Foi encerrada, aos 80 anos, uma das mais proficientes carreiras de zoólogo conhecidas no país, de líder na área de conservação e renovação dos Recursos Naturais, administrador admirável dos dois maiores museus de história natural do Brasil.

Filho de José Cândido de Mello Carvalho e Ana Gabriela de Mello Carvalho, passou sua infância nas fazendas dos tios em Barro Preto (atual Conceição Aparecida, Minas Gerais) e como se destinava à carreira eclesiástica freqüentou o Seminário Diocesano de Guaxupé, também em Minas Gerais, durante três anos. Terminou seus estudos básicos em Franca (São Paulo), no Ginásio Champagnat.

Em 1929 concluiu o Curso Técnico da Escola Superior de Agricultura de Viçosa. Declarou sempre que ali recebera a influência decisiva de três grandes Mestres: Rui Gomes de Morais em Parasitologia, João Moojen de Oliveira em Zoologia e João Geraldo Huhlman em Botânica.

Concluiu o Mestrado em Zoologia nos Estados Unidos da América, na Universidade de Nebraska, em 1940 e o Doutorado na Universidade de Iowa, em 1942. Foi nesta época que iniciou os seus estudos em Hemiptera, especializando-se na familia Miridae, considerando o seu estudo um verdadeiro desafio.

Em 1946 ingressara no Museu Nacional, indo preencher as grandes lacunas ali existentes em face da obrigatoriedade da desacumulação. No mesmo ano iniciou o seu trabalho de campo acompanhando Eduardo Galvão e Pedro Estevam de Lima ao Xingu. Foi a primeira de suas inúmeras excursões pelo País.

A sua longa carreira de Naturalista, Professor Ecólogo e Zoólogo está relacionada no "Memorial de um Naturalista", publicado pela Universidade Federal do Rio de Janeiro em 1994. Permito-me somente destacar alguns fatos e impressões de nosso longo convívio.

Era José Cândido de Mello Carvalho normalmente sério e às vezes áspero; de compleição atlética havia praticado vários esportes, possuindo força excepcional que muito lhe valia nas explorações e excursões; como administrador era extremamente exigente, mas sempre foi justo. Iniciava o seu dia às seis ou sete horas, pela manhã e, freqüentemente era encontrado redigindo ou fazendo anotações, altas horas da noite. Renovou e reabriu ao público o Museu Paraense Emílio Goeldi (1954/55) e o Museu Nacional (de 1955 até 1961).

Conhecedor da fauna brasileira pela observação de campo, fruto de suas numerosas excursões, sabia do comportamento e hábitos da maioria dos mamíferos, aves, répteis e anfíbios, para não citar a entomologia, sua especialização. Corrigiu inúmeras crendices e distorções sobre os nossos animais. Realizou 26 grardes expedições, algumas de vários meses; percorreu $18000 \mathrm{~km}$ em canoa, jipe, lombo de burro e a pé.

Como Entomólogo, grangeou renome internacional publicando o "Catálogo de Mirídeos do Mundo" em cinco volumes. Obra basilar onde, em 1110 páginas, registrou mais de $10 \%$ de todas as espécies do mundo e, provavelmente, $90 \%$ das espécies americanas. Para realizar este levantamento monumental visitou e pesquisou as coleções do Museu Britânico, dos principais museus americanos e 
estudou a fauna asiática, com auxílio de tradutores chineses, japoneses e de outras línguas daquele continente. Comparou e relacionou material nos museus de Paris, Amsterdã, Estocolmo, Helsinqui, Copenhagen, Bruxelas, mais os da Índia, Japão, Havaí, sem esquecer as coleções brasileiras. Descreveu 267 gêneros e 1319 espécies sendo, sem dúvida, a maior autoridade mundial em Miridae.

Como pioneiro e líder na área de Conservação e Proteção, em 1958 compareceu ao Congresso Internacional de Londres onde foi eleito Representante para a América Latina, da União Internacional de Conservação da Natureza.

Ainda em 1958, criou a Fundação Brasileira para a Conservação da Natureza (FBCN) da qual foi Presidente por dois mandatos.

Participou de todas as fases da legislação ambiental destacando-se a Lei de Proteção à Fauna; organizou a primeira "Lista das Espécies de Animais e Vegetais Ameaçadas de Extinção", e a Portaria do IBDF que deu proteção legal aos animais do País, como membro do Conselho Nacional de Pesquisas, onde atingiu a Vice-Presidência.

Foi membro do Instituto do Patrimônio Histórico e Artístico Nacional (ISPHAN), do Conselho Federal de Cultura e Presidente da Câmara de Ciências deste último Conselho.

Conselheiro Relator dos mais importantes processos relativos à Natureza, não podemos deixar de assinalar que foi sob sua orientação que pela primeira vez publicou-se na íntegra "A Viagem Filosófica" de Alexandre Rodrigues Ferreira.

Outra contribuição marcante de José Cândido foi sua colaboração no Grande Dicionário da Língua Portuguesa (conhecido como Aurélio), onde seguindo os precursores como Oscar Monte, Rodolpho von Ihering, Alcides Lourenço Gomes, procurou trazer à consulta popular o que só se encontrava nos meios científicos. Atendendo à diretriz do renomado Aurélio Buarque de Holanda Ferreira, ali colocou uma pequena descrição do animal, de seu habitat e comportamento. Apesar do trabalho gigantesco (mais de 3000 verbetes), permanecem senões que não impediram ser considerado o Dicionário "All new and by far the best in the World" (Publishers Weekly, Estados Unidos da América).

O ilustre professor, pesquisador e zoólogo foi Presidente permanente para os Congressos Internacionais de Entomologia, membro efetivo e honorário das mais importantes Sociedades Científicas, Professor Emérito da Universidade Federal do Rio de Janeiro, com 19 Prêmios e Medalhas onde se destacam as da Word Wild Foundation e da Zoological Society of London. Membro Titular da Academia Brasileira de Ciências desde 1951.

Finalizando este incompleto e imperfeito resumo do que foi a longa e proveitosa vida de José Cândido de Mello Carvalho, é de justiça a presença permanente de sua digna esposa Nilza Freire de Carvalho e de sua filha Iara F. de Mello Carvalho, como apoio decisivo em sua trabalhosa existência.

\section{Prêmios recebidos pelo Dr. J.C. de Mello Carvalho}

Prêmio Cândido Firmino de Melo Leitão - ABC

Prêmio Costa Lima - ABC 
Medalha de Mérito Ex-aluno - Universidade de Viçosa

Honra ao Mérito - SBZ

\section{TRABALHOS PUBLICADOS}

Seiscentos e trinta e dois trabalhos publicados e, ainda 15 no prelo.

\section{VIAGENS AO EXTERIOR}

Vinte e sete viagens ao exterior.

Congressos de Zoologia e Entomologia

Trinta Congressos.

EXPEDIC̣õES No BRAsIL

Vinte e seis expedições.

Solon Leontsinis *

*. Museu Nacional, Universidade Federal do Rio de Janeiro, Quinta da Boa Vista, 20940-040 Rio de Janeiro, Rio de Janeiro, Brasil. 